\title{
Detection of multidrug-resistant enterobacteria simultaneously producing extended-spectrum $\beta$ - lactamases of the PER and GES types isolated at Saint Camille Hospital Center, Ouagadougou, Burkina Faso
}

Mètuor Dabiré Amana ${ }^{1}$, Tiemtoré Rahimatou Yasmine Wend-Kuni ${ }^{{ }^{*}}$, Bangré Yasmine Aminata ${ }^{2}$, Zohoncon Théodora Mahoukédé ${ }^{1}$, Sougué Serge ${ }^{1}$, Zongo Jacob Koudbi ${ }^{1}$ and Simporé Jacques ${ }^{1}$

${ }^{1}$ Laboratory of Biology and Genetics Molecular (LABIOGENE), University Ouaga 1 Pr Joseph KI-ZERBO (UOI-PJKZ), B.P: 03 B.P. 7021 Ouagadougou 03, Burkina Faso.

${ }^{2}$ Laboratory of Applied Biochemistry and Chemistry (LABIOCA), UFR-SVT, University Ouaga 1 Pr Joseph KI-ZERBO, 03 BP 7021 Ouagadougou 03, Burkina Faso.

Received 16 May, 2019; Accepted 22 July, 2019

\begin{abstract}
Resistance to a wide variety of common antibiotics is observed among clinical strains designated as extended-spectrum $\beta$-lactamase (ESBL) producers. These produce enzymatic proteins that effectively inactivate cephalosporins and aztreonam and are a serious global health problem that complicates treatment strategies. Many studies report a high prevalence of ESBL producers among Gram-negative bacilli. The purpose of this work was to identify resistance genes in enterobacterial strains. Gramnegative bacilli resistant to at least one third-generation cephalosporin, aztreonam or showing a synergy image between amoxicillin + clavulanic acid and a third generation cephalosporin were isolated during an antibiogram. Antibiotic resistance was detected for the following antibiotics: Ceftriaxone, Cefotaxime, Ceftazidime and Aztreonam. Classical polymerase chain reaction (PCR) analyzes of Pseudomonas extended resistance (PER) and Guiana extended-spectrum (GES) $\beta$-lactamase genes were performed using specific primers in 60 ESBL-producing isolates. Among 250 strains of Gram negative bacilli collected, 60 strains $(24 \%)$ showed resistance to antibiotics used. Stool samples are a major source of ESBL producers. The highest prevalence of resistant strains (35\%) was observed in Escherichia coli. The GES and PER genes were simultaneously detected at a proportion of $13.33 \%$. This study represents the first detection of PER and GES genes in multidrug-resistant enterobacteria in Burkina Faso.
\end{abstract}

Key words: Broad-spectrum beta-lactamases (ESBLs), Pseudomonas extended resistance (PER) gene, Guiana extended-spectrum (GES) gene, polymerase chain reaction (PCR).

\section{INTRODUCTION}

Enterobacteria, which are mainly responsible for community and nosocomial bacterial infections, have developed mechanisms of resistance to the fatal action of the antibiotics used against them. This resistance can be explained by the excessive and unregulated use of antibiotics, where they are prescribed excessively (Monnet, 2000). This problem is not solved even by the discovery of new, more effective antibiotics and the multi- 
resistance is increasing becoming common (Ouedraogo, 2017).

The majority of Broad-spectrum beta-lactamases (ESBLs) are the result of genetic mutations of natural $\beta$ lactamases (Pana and Zaoutis, 2018). They are very active against penicillins and moderately active against first generation cephalosporins. The genetic mutations at the origin of ESBLs broaden the spectrum of these enzymes and also affect third-generation cephalosporins (ceftazidime, cefotaxime and ceftriaxone, etc.) and monobactams (aztreonam). Virtually all Gram-negative bacteria have a chromosomal gene that codes for a céphalosporinase (Munita and Arias, 2016). ESBLs are mainly found in the Enterobacteriaceae, mainly Escherichia coli and genus Klebsiella, more rarely Serratia, Citrobacter, Enterobacter, Morganella, Proteus, Salmonella, Shigella or non-fermentative Gram-negative bacteria such as Pseudomonas spp., Acinetobacter spp. and others. The majority of ESBLs are derived from TEM and SHV enzymes, but new ESBLs have been described such as cefotaximase (CTX-M), oxacillinase (OXA), Pseudomonas Extended Resistance (PER), Vietnam extended-spectrum $\beta$-lactamase (VEB), Guiana extended-spectrum $\beta$-lactamase (GES), TEM Like Activity (TLA), Brazilian Extended Spectrum $\beta$ lactamases (BES), Serratia fonticola (SFO) and Fecal $E$. coli (FEC) (Cattoir, 2008). The rarer types such as SFO, TLA, PER, BES, GES, are found in Acinetobacter baumanii, Serratia fonticola, Pseudomonas aeruginosa, Klebsiella pneumoniae (Vodovar et al., 2013). ESBLs, because of their mode of distribution, constitute a major threat for West African countries where weak socioeconomic conditions result in poor hygiene conditions, favoring the spread of resistance. It is therefore necessary to determine the presence of genes conferring these resistances. Studies in Burkina have already identified the presence of TEM, SHV and CTX-M genes, which are responsible for bacterial resistance in enterobacteria (Zongo et al., 2015). These genes, although widespread, are not the only ones responsible for bacterial resistance as determined in other countries (Cattoir, 2008). In a context of escalating antibiotic resistance in our country, we must not neglect the search for new ESBLs. This study was conducted with the aim of detecting the presence of PER and GES types of resistances together in enterobacterial strains at Saint Camille Hospital in Ouagadougou, Burkina Faso.

\section{MATERIALS AND METHODS}

\section{Isolation and identification of strains}

The bacterial strains in our study were gram-negative bacilli resistant to a cephalosporin of third-generation or monobactam. These strains were collected between September and October 2018 at the bacteriology Department of the Saint Camille hospital laboratory. Strains were isolated from urine, pus, stool and vulvar specimens, from internal or external patients at Saint Camille Hospital Center of Ouagadougou (HOSCO). The isolates were identified by API 20E tests (BioMérieux S.A., Marcy l'Etoile, France).

\section{Antibiotic sensitivity test and ESBL detection}

Antibiotic sensitivity was tested by the disk diffusion method. Antibiotics were tested on Petri dishes containing Muller Hinton agar. The antibiotic discs used were: aztreonam $(30 \mu \mathrm{g})$ for monobactam, cefotaxime $(30 \mu \mathrm{g})$, ceftriaxone $(30 \mu \mathrm{g})$ and ceftazidime $(30 \mu \mathrm{g})$ for third-generation cephalosporins. Isolates resistant to at least one antibiotic in clinical trials were collected, purified by single colony isolation and stored at $-20^{\circ} \mathrm{C}$ for further analysis. In order to determine the production of ESBL, the antibiotic discs were deposited in such a way as to reveal the synergy action image representing a champagne plug characteristic of the ESBL profile through a synergy test between the thirdgeneration cephalosporins (cefotaxime or ceftazidime) and amoxicillin + clavulanic acid (Jarlier et al., 1988).

\section{Molecular characterization of isolates producing ESBL}

\section{Bacterial DNA extraction}

The extraction was done by the boiling method. The conserved strains are reactivated by culture on the $\mathrm{MH}$ medium for 18-24 h. An isolated colony is taken from the Petri dishes and suspended in 200 $\mu \mathrm{l}$ of distilled water previously aliquoted in labeled eppendorf tubes. The suspension thus obtained is immersed in a water bath $\left(100^{\circ} \mathrm{C}\right.$ for $15 \mathrm{~min}$ ) in order to release the genetic material. The suspension is then centrifuged at $12,000 \mathrm{rpm}$ for $10 \mathrm{~min}$ and the supernatant containing the released DNA is transferred to a new eppendorf tube and stored at $-20^{\circ} \mathrm{C}$ until use.

\section{Detection of PER and GES genes}

All isolates with antibiotic resistance or showing a synergy image were screened for the gene encoding the $\beta$-lactamase of the PER and GES famillies. The crude DNA extracts obtained after extraction was used for the detection of the gene and the Green Master Mix polymerase chain reaction (PCR) was used. The reaction volume was prepared for $25 \mu \mathrm{l}$ as follows: $12.5 \mu \mathrm{l}$ of Green master mix $+0.5 \mu \mathrm{l}$ of primer $\mathrm{F}+0.5 \mu \mathrm{l}$ of primer $\mathrm{R}+10.5 \mu \mathrm{l}$ of distilled water $+1 \mu$ of DNA extracted. PCR was performed with the Gene Amp System PCR 9700 thermocycler (Applied Biosystems, California, USA). The following primer sequences were used: GES1 F: ATGCGCTTCATTCACGCAC and GES-1 R: ATGAATGTCATTATAAAAGC and PER-1 R: AATTTGGGCTTAGGGCAGAA.

The amplification was carried out according to the following program: Initial denaturation at $95^{\circ} \mathrm{C}$ for $5 \mathrm{~min}$, followed by denaturation at $95^{\circ} \mathrm{C}$ for $60 \mathrm{~s}$, annealing at $50^{\circ} \mathrm{C}$ for $60 \mathrm{~s}$, extension at $68^{\circ} \mathrm{C}$ for $1 \mathrm{~min}$, to finish with a final extension at $68^{\circ} \mathrm{C}$ for $5 \mathrm{~min}$

*Corresponding author. E-mail: thiombianomina@yahoo.fr. Tel: +22671853803.

Author(s) agree that this article remain permanently open access under the terms of the Creative Commons Attribution License 4.0 International License 


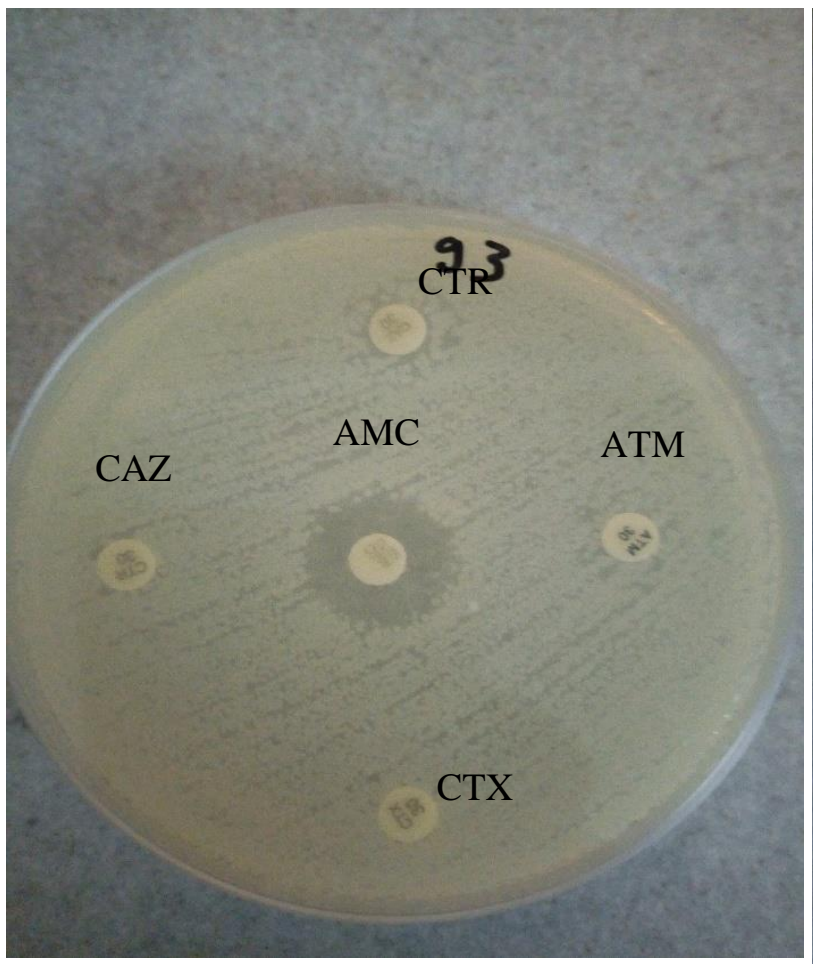

(A)

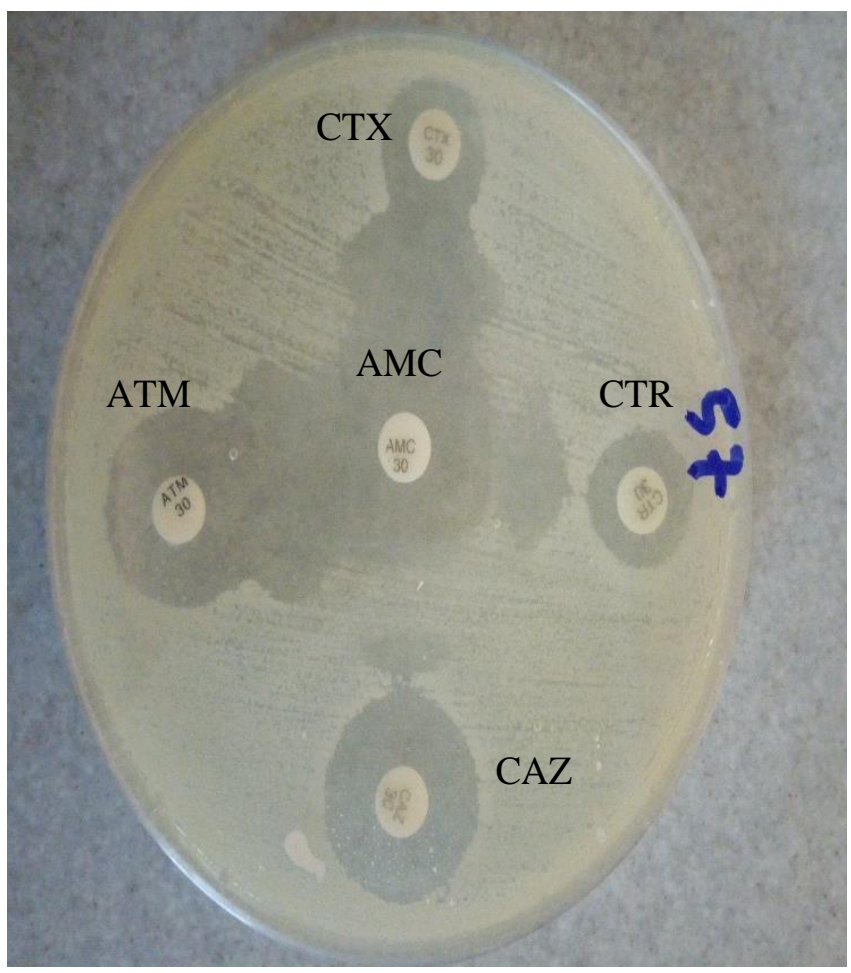

(B)

Figure 1. (a) Petri dish with a strain of enterobacteria resistant to CTR, CAZ, CTX, ATM. (b) Petri dish representing a synergistic image characteristic of an ESBL.

this cycle was repeated 30 times.

\section{Agarose gel electrophoresis}

Electrophoretic migration at 120 volts for 30 min was performed on a $1 \%$ agarose gel in the presence of ethidium bromide. A molecular weight marker of $1000 \mathrm{~Pb}$ was used as a reference. The resulting bands were observed under UV light from the GENE FLASH apparatus.

\section{RESULTS}

\section{Bacterial strains and antibiotic susceptibility testing}

In this study, 24\% (60/250) Enterobacteriaceae strains resistant to at least one third generation cephalosporin or aztreonam and / or showing a synergy image were detected (Figure 1). Among the 60 strains of resistant enterobacteria, the following species were detected (Table 1). Most of the resistant strains came from cytobacteriological examinations of the urine $(50 \%)$. Most of the resistant strains were from out patients at Saint Camille Hospital with $51.64 \%$. The age of patients harboring the strains with resistance ranged from 22 days to 95 years with an average age of 36.66 years. The sex ratio $\mathrm{H} / \mathrm{F}$ was 0.71 . The distribution of the strains according to their resistance or to the presence of a synergy image is represented in Table 2 . The resistance rates observed were: $65 \%$ for cefotaxime, $63.33 \%$ for ceftriaxone, $50 \%$ for ceftazidime and $60 \%$ aztreonam.

\section{PER and GES gene amplification and electrophoresis}

The search for the PER gene by classical PCR with specific primers showed that 9 strains (15\%) harbor this gene. About 1000 bp bands were observed after migration and visualization of the PCR products (Figure 2). $13.33 \%$ of the multidrug-resistant enterobacterial strains produced ESBLs of PER and GES types simultaneously and they were all from patients over 30 years of age, whereof $75 \%$ were men. Isolates that produce ESBL-PER and ESBL-GES at the same time are much more common in stool with $62.5 \%$ and come from external patients at the HOSCO. The distribution of genes according to bacterial species is shown in Table 3 .

\section{DISCUSSION}

The objective of this study was to detect Gram-negative bacteria that simultaneously produce ESBL PER and GES types at Saint Camille Hospital in Ouagadougou. We observed the ESBL phenotype in five bacterial 
Table 1. Frequency of bacterial strains.

\begin{tabular}{lcc}
\hline Species & Number & Percentage \\
\hline Escherichia coli & 21 & 35 \\
Klebsiella pneumoniae & 18 & 30 \\
Enterobacter cloacae & 6 & 10 \\
Enterobacter aerogenes & 1 & 1.67 \\
Citrobacter freundii & 3 & 5 \\
Citrobacter brakii & 1 & 1.67 \\
Citrobacter youngae & 1 & 1.67 \\
Proteus mirabilis & 4 & 6.66 \\
Salmonella arizona & 1 & 1.67 \\
Serratia marescens & 4 & 6,66 \\
Total & 60 & 100 \\
\hline
\end{tabular}

Table 2. The distribution of strains according to their resistance or the presence of a synergy image.

\begin{tabular}{lccccc}
\hline Strain & ATM resistant & CAZ resistant & CTX resistant & CTR resistant & Synergy image \\
\hline Escherichia coli & 13 & 12 & 15 & 15 & 4 \\
Klebsiella pneumoniae & 12 & 8 & 11 & 12 & 0 \\
Enterobacter cloacae & 6 & 4 & 4 & 4 & 0 \\
Enterobacter aerogenes & 0 & 1 & 0 & 0 & 0 \\
Citrobacter freundii & 1 & 2 & 3 & 1 & 0 \\
Citrobacter brakii & 0 & 0 & 0 & 1 & 0 \\
Citrobacter youngae & 0 & 0 & 0 & 2 & 2 \\
Proteus mirabilis & 0 & 0 & 2 & 0 & 0 \\
Salmonella arizona & 1 & 0 & 1 & 3 & 0 \\
Serratia marescens & 3 & 3 & 3 & 38 & 7 \\
Total & 36 & 30 & 39 & & \\
\hline
\end{tabular}

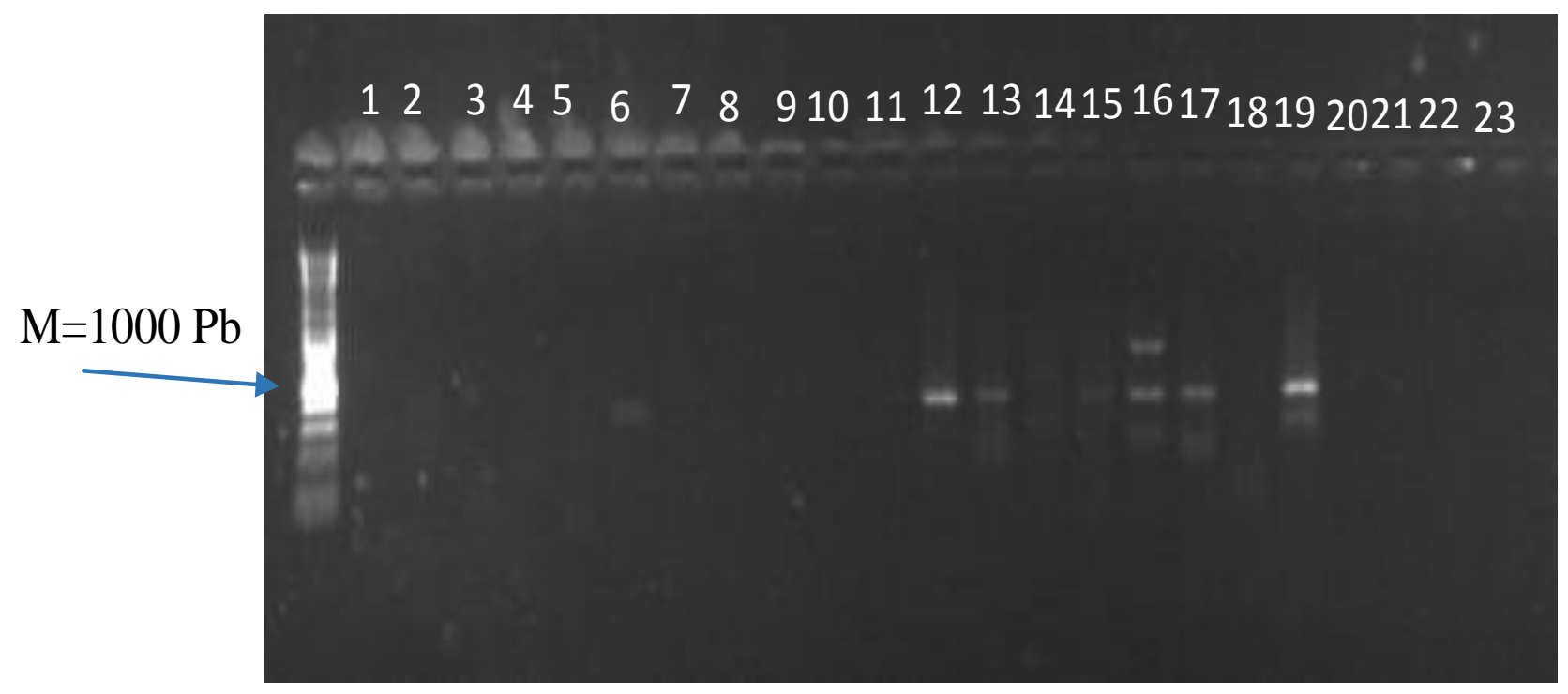

Figure 2. PCR agarose gel from PER and GES. Legend: 1 to 13 correspond to the PER gene; $14=$ negative control; 15 to 23 correspond to the gene GES, M = Molecular Weight Marker (GeneRuler 1Kb DNA Ladder). 
Table 3. Gene distributions according to bacterial species.

\begin{tabular}{lc}
\hline Species & GES and PER gene \\
\hline E. coli & 2 \\
Enterobacter cloacae & 3 \\
Salmonella arizona & 1 \\
Citrobacter freundii & 1 \\
Serratia marescens & 1 \\
Total & 8 \\
\hline
\end{tabular}

genera. The prevalence of resistant strains was $24 \%$ of isolated bacteria comprising of $25 \%$ E. coli, $37.5 \%$ Enterobacter cloacae, $12.5 \%$, Citrobacter freundii; $12.5 \%$ Salmonella arizona and $12,5 \%$ Serratia marescens. All the bacteria studied showed a high level of resistance to the antibiotics used. Several multiresistant strains were observed in this study. This multidrug resistance can be explained by the fact that the genes responsible for these resistances can be carried by the same plasmid, by the coexistence of several resistance mechanisms, or by the production of several enzymatic types (Harbottle et al., 2006; Boerlin and Reid-Smith, 2008; Muylaert and Mainil, 2012). The resistance rates observed are very high for some antibiotics [cefotaxime (65\%), ceftriaxone (63.33\%), ceftazidime (50\%) and aztreonam (60\%)] compared to those observed in developed countries but are approaching resistance rates reported in developing countries (Philippon and Arlet, 2006). This high level of resistance is a consequence of the acquisition of antibiotic resistance factors that is generally secondary to the misuse and uncontrolled use of these antibiotics (Boerlin and Reid-Smith, 2008; Muylaert and Mainil, 2012). The absence of routine surveillance in most countries and especially in the West African region does not allow for a good estimate of ESBL proportions among the strains isolated during infections. Other studies have reported the high incidence of resistance as in Ghana where half of the enterobacteria $(49.4 \%)$ isolated from the various infections diagnosed at Korle-Bu Hospital were producing ESBL (Feglo et al., 2013). In Togo 66\% of E. coli strains isolated from urinary tract infections had the ESBL phenotype (Kubo et al., 2014). These results demonstrate the emergence and dissemination of antibiotic-resistant germs, generally because of the poor living and hygiene conditions observed in developing countries (Ouedraogo, 2017). The results on antibiotic susceptibility [cefotaxime (65\%), ceftriaxone (63.33\%), ceftazidime (50\%) and aztreonam (60\%)] confirm the results of earlier work on the high prevalence of enterobacteria resistance to $\beta$-lactams in developing countries, which is higher than those in developed countries. In this study, the majority of ESBL producing strains $(51.67 \%)$ were isolated from out-patients at Saint Camille Hospital. This can be explained by the lack of strict rules for the acquisition of antibiotics in developing countries which means that everyone can have access to even broad-spectrum antibiotics without any medical prescription (Nugent and Okeke, 2010). In all West African countries, antibiotics are sold, like many other medicines, in popular markets and these drugs are known as street drugs (Sirinavin and Dowell 2004; Herindrainy et al., 2011). Self-medication and ignorance promote sharing of antibiotics between individuals based on similar clinical signs.

The CTX, SHV and TEM genes involved in bacterial resistance are the most abundant and documented genes in West Africa (Pieboji, 2007; Zhuo et al., 2013; Metuor-dabire, 2014), but besides these genes, rare genes such as PER, GES, SFO, TOHO, VEB etc are also responsible for resistance. The results show for the first time in Burkina and West Africa the presence of PER and GES genes simultaneously in enterobacterial strains. Extended spectrum $\beta$-lactamase (ESBL) PER was detected for the first time in 1993 in a $P$. aeruginosa isolate from a Turkish patient in France (Nordmann et al.; 1993). This enzyme is weakly related to other ESBLs and confers resistance to penicillins, cefotaxime, ceftriaxone, ceftazidime and monobactam-aztreonam, but does not confer carbapenem and cephamycin resistance. Its activity is inhibited by clavulanic acid (Nordmann and Naas, 1994). The bla $a_{\text {PER }}$ gene is widespread in Acinetobacter spp., $P$. aeruginosa and Salmonella enterica serovar Typhimurium in Turkey (Vahaboglu et al., 1996, 1997) and has also been detected in Providencia rettgeri in that country (Bahar et al., 2004). In addition, PER-1 has been identified in Acinetobacter sp. isolated in Korea (Yong et al., 2003). In Italy, PER-1 was detected in isolates of $P$. aeruginosa, Alcaligenes faecalis and Proteus mirabilis (Pereira et al., 2000; Pagani et al., 2004). In our study, the PER gene was found in E. coli, Enterobacter cloacae, Enterobacter aerogenes, Serratia marescens, Citrobacter freundii and Salmonella arizona with a predominance in Enterobacter cloacae. The majority of our PER-producing strains were not only resistant to third-generation cephalosporins and monobactams, but also exhibited a multiresistant phenotype, which corroborates the results obtained in Italy by Pagani et al. (2004). In this study, we have demonstrated the presence of the GES gene, an enzyme weakly similar to another Ambler class, A $\beta$-lactamases (Ambler, 1980), in particular to ESBL localized in a plasmid, identified so far in enterobacteriaceae. As for class A ESBL, GES has been identified in $K$. pneumoniae, a species that remains the main reservoir of enzymes worldwide, for unknown reasons (Poirel et al., 2000). GES has 23 variants that are identified. In this study, we describe clinical isolates of K. pneumoniae, $E$. coli, Enterobacter cloacae, Serratia marescens, Citrobacter youngae, Citrobacter freundii, Salmonella arizona and Citrobacter brakii producing Ambler class A enzyme, GES. This enzyme has been reported in Europe 
in K. pneumoniae (Poirel et al., 2000) and Pseudomonas aeruginosa (Dubois et al., 2002). In most ESBL, GES - 1 does not hydrolyze aztreonam (Naas et al., 2008). GES-2 hydrolyzes the carbapenems and is not sensitive to inhibitors, due to a 2-bp substitution, leading to a single change of Gly170Asn in the $\Omega$ loop of the catalytic site. GES - 9, which differs from GES - 1 by the change of Gly243Ser, does not hydrolyze carbapenems but expands monobactam activity (Poirel et al., 2005). Our results show that $62.5 \%$ of our strains possessing the GES gene hydrolyzes aztreonam, which could suggest that it is GES-9. $13.33 \%$ of the multidrug-resistant enterobacterial strains produced ESBLs of the PER and GES types simultaneously. This corroborates the results obtained by Metuor-Dabire et al. (2018), which found 11 multidrug-resistant ESBL-producing strains harboring both CTX-M and SHV as well as TEM and SHV (MètuorDabiré et al., 2018).

Other studies have detected the presence of its genes in an isolated way in bacterial strains (Pereira et al., 2000; February et al., 2003), our study is the first to have highlighted the simultaneous presence of two types of ESBL, PER and GES.

\section{Conclusion}

The aim of this work was to detect extended spectrum $\beta$ lactamase-producing Enterobacteriaceae (ESBL) at Saint Camille Hospital in Ouagadougou. The isolated bacteria have high levels of resistance to the $\beta$-lactams tested. The prevalence of third generation cephalosporin resistant bacteria, aztreonam and / or synergy image is $24 \%$. In view of these results it appears that ESBLs play an important role in bacterial resistance and this is accentuated by the appearance of mutants of these often more dangerous enzymes that compromise health care.

\section{CONFLICT OF INTERESTS}

The authors have not declared any conflict of interests.

\section{REFERENCES}

Ambler RP (1980). The structure of $\beta$-lactamases', Philosophical Transactions of the Royal Society of London. B, Biological Sciences 289(1036):321-331.

Bahar G, Erac B, Mert A, Gülay Z (2004). PER-1 Production in a Urinary Isolate of Providencia rettgeri. Journal of Chemotherapy 16(4):343-346.

Boerlin P, Reid-Smith RJ (2008). 'Antimicrobial resistance: its emergence and transmission. Animal Health Research Reviews 9(2):115-126.

Cattoir V (2008). Les nouvelles beta-lactamases à spectre étendu (BLSE)'. Pathologie infectieuse en réanimation. MAPAR. P. 208.

Dubois V, Poirel L, Marie C, Arpin C, Nordmann P, Quentin C (2002). 'Molecular characterization of a novel class 1 integron containing bla(GES-1) and a fused product of aac3-lb/aac6'-Ib' gene cassettes in Pseudomonas aeruginosa', Antimicrobial agents and chemotherapy. American Society for Microbiology 46(3):638-645.

Feglo $\mathrm{P}$, Adu-Sarkodie $\mathrm{Y}$, Ayisi L, Jain R, Spurbeck RR, Springman AC, Walk ST (2013). Emergence of a Novel Extended-SpectrumLactamase ( ESBL ) - Pathogenic Escherichia coli in Kumasi, Ghana. Journal of Clinical Microbiology 51(2):728-730.

Harbottle H, Thakur S, Zhao S, White DG (2006). Genetics of Antimicrobial Resistance. Animal Biotechnology 17(2):111-124.

Herindrainy P, Randrianirina F, Ratovoson R, Hariniana ER, Buisson Y, Genel N, Richard V (2011). Rectal Carriage of Extended-Spectrum Beta-Lactamase-Producing Gram- Rectal Carriage of ExtendedSpectrum Beta-Lactamase- Producing Gram-Negative Bacilli in Community Settings in Madagascar. PLoS ONE 6(7):e22738.

Jarlier V, Nicolas MH, Fournier G, Philippon A (1988). Extended BroadSpectrum-Lactamases Conferring Transferable Resistance to NewerLactam Agents. Reviews of Infectious Disease 10(4):867-878.

Kubo T, Kitabata H, Komukai K, Matsuo Y, Ozaki Y, Takarada S, Ueno $S$ (2014). Corrigendum to "Occurrence of infection following prostate biopsy procedures in Japan: Japanese Research Group for Urinary Tract Infection ( JRGU ) e A multi-center retrospective study. Journal of Infection and Chemotherapy 20(10):660.

Mètuor-dabiré A (2014). Caractérisations moléculaire et cinétique des types de $\beta$-lactamases à spectre élargi (BLSE) de souches bactériennes collectées au Centre Hospitalier Universitaire Pédiatrique Charles De Gaulle (CHUP-CDG) de Ouagadougou', Thèse Présentée pour obtenir le grade de Docteur de I' Université de Ouagadougou.

Mètuor Dabiré A, Zongo J, Kaboré B, Zèba B, Baucher M, El Jaziri M, Simporé J (2018). Resistance to $\beta$-Lactamines by Gram Negative Bacteria, Producing Several Types of Enzymes, Isolated from Urines in Pediatric Center of Ouagadougou in Burkina Faso. International Journal of Microbiology and Biotechnology 3(4):95-98.

Monnet DL (2000). Consommation d'antibiotiques et résistance bactérienne', in Annales françaises d'anesthésie et de réanimation. Elsevier, pp. 409-417.

Munita JM, Arias CA (2016). Mechanisms of Antibiotic Resistance. Microbiology Spectrum 4(2):10.1128.

Muylaert A, Mainil JG (2012). Résistances bactériennes aux antibiotiques: les mécanismes et leur «contagiosité. Université de Liège. pp. 109-123.

Naas T, Naas L, Nordmann P (2008). Minor extended-spectrum b lactamases. Clinical Microbiology and Infection 14:42-52.

Nordmann P, Naas L, Nordmann P (1993). Characterization of a novel extended-spectrum beta-lactamase from Pseudomonas aeruginosa. Antimicrobial Agents and Chemotherapy 37(5):962-969.

Nordmann P, Naas T (1994). Sequence analysis of PER-1 extendedspectrum beta-lactamase from Pseudomonas aeruginosa and comparison with class A beta-lactamases. Antimicrobial Agents and Chemotherapy 38(1):104-114.

Nugent R, Okeke IN (2010). Editorial When medicines fail: recommendations for curbing antibiotic resistance. Journal of Infection in Developing Countries 4(6):355-356

Ouedraogo A (2017). Prévalence, circulation et caractérisation des bactéries multirésistantes au Burkina Faso. Médecine humaine et pathologie. Université Montpellier, 2016. Français. ffNNT: 2016MONTT001ff. fftel-01476152

Pagani L, Mantengoli E, Migliavacca R, Nucleo E, Pollini S, Spalla M, Rossolini GM (2004). Multifocal detection of multidrug-resistant Pseudomonas aeruginosa producing the PER-1 extended-spectrum beta-lactamase in Northern Italy. Journal of Clinical Microbiology 42(6):2523-2529.

Pana ZD, Zaoutis T (2018). Treatment of extended-spectrum ?lactamase-producing Enterobacteriaceae (ESBLs) infections: what have we learned until now? [version 1; peer review: 2 approved]', F1000Research 7(1347). doi: 10.12688/f1000research.14822.1.

Pereira M, Perilli M, Mantengoli E, Luzzaro F, Toniolo A, Rossolini GM, Amicosante G (2000). PER-1 Extended-Spectrum $\beta$-Lactamase Production in an Alcaligenes faecalis Clinical Isolate Resistant to Expanded-Spectrum Cephalosporins and Monobactams from a Hospital in Northern Italy. Microbial Drug Resistance 6(1):85-90.

Philippon A, Arlet G (2006). [Beta-lactamases of Gram negative bacteria: never-ending clockwork!]. Annales de Biologie Clinique 64(1):37-51. 
Pieboji JG (2007). Caractérisation des beta-lactamases et leur inhibition par les extraits de plantes médicinales. Thèse présentée en vue de l'obtention du diplôme de Doctorat ès Sciences en Biochimie.

Poirel L, Le Thomas I, Naas, T, Karim A, Nordmann P (2000). 'Biochemical Sequence Analyses of GES-1, a Novel Class A Extended-Spectrum $\beta$-Lactamase, and the Class 1 Integron In52 from Klebsiella pneumoniae. Antimicrobial Agents and Chemotherapy 44(3):622-632.

Poirel L, Cabanne L, Vahaboglu H, Nordmann P (2005). Genetic environment and expression of the extended-spectrum betalactamase blaPER-1 gene in gram-negative bacteria. Antimicrobial Agents and Chemotherapy 49(5):1708-1713.

Vahaboglu H, Yaman A, Kaygusuz A (1996). Characterization of multiple-antibiotic-resistant Salmonella typhimurium stains: molecular epidemiology of PER-1-producing isolates and evidence for nosocomial plasmid exchange by a clone. Journal of Clinical Microbiology 34(12):2942-2946.

Vahaboglu H, Oztürk R, Aygün G, Coşkunkan F, Yaman A, Kaygusuz A, Otkun M (1997). Widespread detection of PER-1-type extendedspectrum beta-lactamases among nosocomial Acinetobacter and Pseudomonas aeruginosa isolates in Turkey: a nationwide multicenter study. Antimicrobial Agents and Chemotherapy 41(10):2265-2269.

Vodovar D, Marcadé G, Raskine L, Malissin I, Mégarbane B (2013). Entérobactéries productrices de bêta-lactamases à spectre élargi : épidémiologie, facteurs de risque et mesures de prévention. La Revue de Médecine Interne 34(11):687-693.
Yong D, Shin JH, Kim S, Lim, Y, Yum JH, Lee K, Bauernfeind A (2003). High prevalence of PER-1 extended-spectrum beta-lactamaseproducing Acinetobacter spp. in Korea. Antimicrobial Agents and Chemotherapy 47(5):1749-1751.

Zhuo C, Li, XQ, Zong ZY, Zhong, NS (2013). Epidemic Plasmid Carrying bla CTX-M-15 in Klebsiella penumoniae in China. PLoS ONE 8(1):1-8.

Zongo KJ, Dabire AM, Compaore LG, Sanou I, Sangare L, Simpore J, Zeba, B (2015). First detection of bla TEM, SHV and CTX-M among Gram negative bacilli exhibiting extended spectrum $\beta$-lactamase phenotype isolated at University Hospital Center, Yalgado Ouedraogo, Ouagadougou, Burkina Faso. African Journal of Biotechnology 14(14):1174-1180. 